\title{
In need of special care: adolescent and young adult patients with cancer
}

\author{
Michael N. Dworzak
}

Received: 20 February 2018 / Accepted: 20 February 2018 / Published online: 2 March 2018

C Springer-Verlag GmbH Austria, part of Springer Nature 2018

The adolescent and young adult (AYA) period is generally defined as the range between 15-39 years of age [1]. Awareness of the special medical needs of this age group has come into focus as represented by the exceptional increase of publications in the field, ranging from six in 1997 to 59 in 2007, and to 269 in 2017 (MEDLINE ${ }^{\circledR}, 07$ February 2018). AYA patients suffer from a spectrum of cancers that are either similar to 'paediatric' cancers (such as acute lymphoblastic leukaemia [ALL], sarcoma, and brain tumours) or 'adult' tumours (such as breast cancer and melanoma) or are cancers quite unique to their age group (such as testicular cancer and bone tumours; [1]). In addition, the peak in incidence of certain cancers like Hodgkin lymphoma or germ cell tumours falls into the AYA period [2].

Cancer in AYA is four times more numerous than that in the paediatric age group-with about 66,000 patients in Europe each year [2]. However, as compared to their younger counterparts, outcome of AYA patients is less favourable in several cancer subtypes $[2,3]$. This has to do, both, with cell-biologic and host factors, as well as with treatment associated factors including lack of clinical trial participation as well as limited familiarity of oncologists with specific aspects of disease management due to rareness of certain cancer entities [1,3-5]. Directly related to these aspects is the traditional separation of medical services into the paediatric field on the one hand and adult medicine on the other. Adequate AYA cancer management would need more bridging interfaces [2]. This has begun to come into reality as specialized AYA

Assoc. Prof. M. N. Dworzak, M.D., Ph.D. (凹)

Children's Cancer Research Institute and St. Anna Children's

Hospital, Department of Pediatrics, Medical University of

Vienna, Kinderspitalgasse 6, 1090 Vienna, Austria

dworzak@stanna.at care programs in the US and some European countries, but not everywhere [6]. Importantly, data are emerging, how treatment practice influenced by either paediatric or adult therapeutic strategies may improve outcome in certain AYA cancers [3]. The article of Ampatzidou and coauthors in this issue of memo summarizes current views on this regarding acute leukaemias [7].

A further checkpoint of appropriate AYA care is knowledge of the special needs and challenges of this age group in terms of psychosocial support and respective services, which particularly might influence overall quality of life during and after cancer treatment. The type of support and ancillary services that are required differ from those of paediatric or older adult patients. AYA face the intersection of the cancer experience with a period of rapid biological and psychosocial development [8]. Recurrent themes of relevance during time of cancer care are about autonomy and independence, peer pressure, social and sexual maturation, partnership, fertility, educational or occupational pursuits, career planning, as well as finances (compare [8]). Frequently, younger AYAs at the age intersection between paediatric and adult medicine feel germane neither to paediatric, nor to adult cancer care facilities. Additional emotional pressure often results from a re-emerging dependence on parents and by being still too young for a fully autonomous participation in adult processes despite having passed the age of legal majority [3]. Hence, it is well established that AYA are at special risk for distress, depression, and anxiety in conjunction with their cancer treatment $[3,8]$.

While such psychological factors can affect lifelong self-image and emotional wellbeing, also physical adverse and late effects of treatment may impact survivors [3]. In this respect it has been shown that AYAs desire for more, rather than less, information 
specially about fertility, sexual functioning, social networks of survivors, re-entering or revising educational/career goals [9]. Again, appropriate aftercare of AYA is a special need where more bridging interfaces between paediatric and adult medicine is urgently needed. In this issue of memo, Bardi and Kager delineate guidelines of long-term follow-up care after childhood cancer [10]. Much of this impacts on care of cancer survivors in the age of AYA. The goals are similar-and as is relevant in the context of fertility and its preservation-as health care providers we need to focus on the special peculiarities of AYA because: it's not too late [11].

Conflict of interest M.N. Dworzak declares that he has no competing interests.

\section{References}

1. Sender L, Zabokrtsky KB. Adolescent and young adult patients with cancer: a milieu of unique features. Nat Rev Clin Oncol. 2015;12:465-80.

2. Desandes E, Stark DP. Epidemiology of adolescents and young adults with cancer in Europe. Prog Tumor Res. 2016;43:1-15.

3. Place AE, Frederick NN, Sallan SE. Therapeutic approaches to haematological malignancies in adolescents and young adults. BrJ Haematol. 2014;164(1):3-14.

4. Davis LE, Janeway KA, Weiss AR, Chen YE, Scharschmidt TJ, Krailo M, Glade Bender JL, Kopp LM, Patel SR, Schwartz GK, Horvath LE, Hawkins DS, Chuk MK, Reinke DK, Gorlick RG, Randall RL. Clinical trial enrollment of adolescents and young adults with sarcoma. Cancer. 2017;123(18):3434-40.

5. Rotz SJ, Nagarajan R, Sorger JI, Pressey JG. Challenges in the treatment of sarcomas of adolescents and young adults. JAdolesc Young Adult Oncol. 2017;6(3):406-13.
6. Ferrari A, Barr RD. International evolution in AYA oncology: current status and future expectations. Pediatr Blood Cancer. 2017;64(9):e26528.

7. Ampatzidou M, Kelaidi C, Dworzak MN, Polychronopoulou $\mathrm{S}$. Adolescents and young adults with acute lymphoblastic leukemia and acute myeloid leukemia: characteristics and treatment outcome. Memo. 2018;11. https://doi.org/10. 1007/s12254-017-0345-1.

8. Lang MJ, David V, Giese-Davis J. The age conundrum: a scoping review of younger age or adolescent and young adult as a risk factor for clinical distress, depression, or anxiety in cancer. J Adolesc Young Adult Oncol. 2015;4(4):157-73.

9. Barnett M, McDonnell G, DeRosa A, Schuler T, Philip E, Peterson L, Touza K, Jhanwar S, Atkinson TM, Ford JS. Psychosocial outcomes and interventions among cancer survivors diagnosed duringadolescenceand young adulthood: a systematic review. J Cancer Surviv. 2016;10(5):814-31.

10. Bardi E, Kager L. Novel guidelines on surveillance for breast cancer, cardiomyopathy, male gonadotoxicity, and premature ovarian insufficiency from the PanCare and International Guideline Harmonization Group on longterm follow-up after cancer in childhood. Memo. 2018;11. https://doi.org/10.1007/s12254-018-0387-z.

11. Murphy D, Orgel E, Termuhlen A, Shannon S, Warren K, Quinn GP. Why healthcare providers should focus on the fertility of AYA cancer survivors: it's not too late! Front Oncol. 2013;7(3):248.

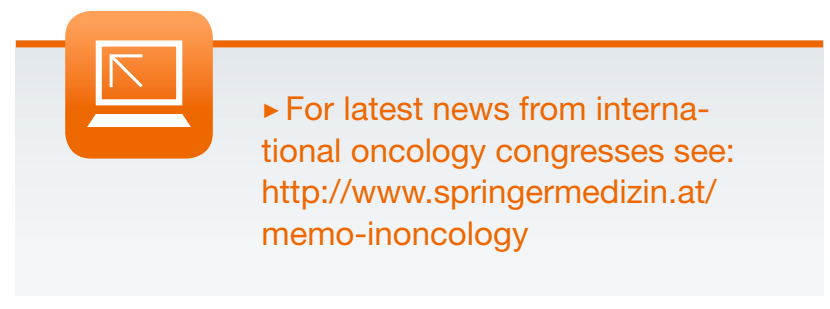

